International Journal of Dairy Processing \& Reseach (JJDPR)

\title{
Managing Transition Dairy Cows for a Less Stressful Lactation: The Nocturnal Crave
}

Akbar Nikkhah

Perspective Article

Chief Highly Distinguished Professor, Department of Animal Sciences, Faculty of Agricultural Sciences, University of Zanjan, National Elite Foundation, Iran.

\begin{abstract}
Nocturnal feeding and eating are discussed as an innovative feasible strategy to improve postpartum appetite and nutrient intake. This can inturn largely attenuate metabolic pressures of high-merit lactation on the already physiologically stressed dairy cows. Such an eased transition from pregnancy into lactation can help optimize milk production persistency and cow health and longevity.
\end{abstract}

Keywords: Nocturnal Feeding; Transition Cow; Physiology; Lactation.

\section{*Corresponding Author:}

Akbar Nikkhah,

Chief Highly Distinguished Professor, Department of Animal Sciences, Faculty of Agricultural Sciences, University of Zanjan, National Elite Foundation, Iran.

Tel: +98-24-33052801

Fax: +98-24-33053202

E-mail: anikkha@yahoo.com nikkhah@znu.ac.ir

Recieved: April 11, 2015

Published: May 05, 2015

Citation: Akbar Nikkhah (2015) Managing Transition Dairy Cows for a Less Stressful Lactation: The Nocturnal Crave. Int J Dairy Process Res. 2(4), 16-17. doi: http://dx.doi.org/10.19070/2379-1578-150006

Copyright: Akbar Nikkhah ${ }^{\circ}$ 2015. This is an open-access article distributed under the terms of the Creative Commons Attribution License, which permits unrestricted use, distribution and reproduction in any medium, provided the original author and source are credited.

\section{Introduction}

Recent discoveries did reveal the significance of timing of circadian feeding and eating on diurnal rhythms of intake, rumen fermentation and peripheral metabolism [1-4]. As a result, milk production was improved by nocturnal vs. morning total mixed ration provision in once-daily fed lactating dairy cows [3, 4]. This article elaborates on mechanistic and pragmatic benefits of nocturnal rhythmic feeding for establishing rhythmic eating behaviour, rumen fermentation capacity and microbial production, milk energy output, and most importantly, desirable animal health and welfare.

\section{Elaborations}

The transition period covering about 3 weeks prepartum through 3 weeks postpartum, highlights a critical physiological phase the success of which determines the healthfulness of the whole lactation and indeed the entire cow life efficiency. This phase is characterized by dramatic shifts in mammary growth and activation, hepatic substrate overflux, splanchnic nutrient utilization, and risks of several economy-threatening metabolic disorders and certainly immune deficiency. A key predisposing factor of the above risks is depressed nutrient intake exacerbated by a very slow pace in feed intake increase following parturition, when compared to increased milk production [6]. As such, any candidate strategy aiming to attenuate periparturient stresses on cow physiology must be able to improve feed intake the foremost.

Extensive recent research demonstrated that nocturnal vs. morning feed provision to high-producing dairy cows was able to create a considerable crave for feed intake, causing once-daily cows to eat as much as $70 \%$ of their total daily intake within the first 3-h post-feeding [1]. This was significantly greater than that of the morning-fed cows. As a result, postprandial sharper increases in rumen concentrations of volatile fatty acids and peripheral levels of energy-producing metabolites occurred in nocturnally-fed cows [5]. A sharp postprandial decline in blood glucose by nocturnal feeding established the crave for feed in night-fed dairy cows.

Accordingly, nocturnal fresh feed provision is theorized to help deterministically establish optimal rhythms in feed intake, rumen conditions, and splanchnoperipheral metabolism in transition cows undergoing moderate adaptations in rumen and host physiology. This has a large capacity to create optimal rhythms in rumen and intermediary metabolism that better fit the dramatically shifted cow status from gestation into lactation. Such an improved appetite and energy intake will in consequence attenuate negative nutrient balance and modulate visceral fat mobilization. The latter can indeed reduce stressors release to liver and help hepatic cells effectively accommodate the overmobilized unsolicited guests from abdominal adipots of mainly fatty acids and proteins of different nature (e.g., adipokines). The result will be decreased risks from fatty liver and inflammation. 


\section{Implication}

Nocturnal feeding is introduced as a global strategy to ease metabolic transition from pregnancy through lactation peak. Such a feasible approach can serve dairy cow health and economy mainly through optimizing circadian rhythms of nutrient intake and metabolism.

\section{Acknowledgment}

The Ministry of Science Research and Technology, National Elite Foundation, and University of Zanjan are thanked for supporting the author's global programs of optimizing science edification in the third millennium.

\section{References}

[1]. Nikkhah A. (2013). Review: Chronophysiology of ruminant feeding behavior and metabolism: an evolutionary review. Biol. Rhythm Res. 44(2): 197-218.

[2]. Nikkhah A. (2014). Timing of feeding: a postmodern management strategy to modulate chronophysiological rhythms in rumen fermentation kinetics. Biol. Rhythm Res. 45(4): 533-540. DOI:10.1080/09291016.2013.870756.

[3]. Nikkhah A, Furedi CJ, Kennedy AD, Crow GH, Plaizier JC (2008). Effects of feed delivery time on feed intake, rumen fermentation, blood metabolites and productivity of lactating cows. J. Dairy Sci. 91: 1-12.

[4]. Nikkhah A, C Furedi, A Kennedy, K Wittenberg, JC Plaizier. (2010). Feed delivery at $2100 \mathrm{~h}$ vs. $0900 \mathrm{~h}$ for lactating dairy cows. Can. J. Anim. Sci. 91(1):113-122.

[5]. Nikkhah A. (2012). Timing of feed presentation entrains periprandial rhythms of energy metabolism indicators in once-daily fed lactating cows. Biol. Rhythm Res. 43(6): 651-661. http://dx.doi.org/10.1080/09291016. 2011.631773.

[6]. NRC (2001). National Research Council. Nutrient Requirements of Dairy Cattle. 7 th rev. ed. National Acad. Sci. Washington, DC. 